\title{
A geometric property for a class of meromorphic analytic functions
}

\section{Rabha W Ibrahim ${ }^{1 *}$ and Janusz Sokół}

\section{"Correspondence:}

rabhaibrahim@yahoo.com

${ }^{1}$ Institute of Mathematical Sciences,

University Malaya, Kuala Lumpur,

50603, Malaysia

Full list of author information is

available at the end of the article

\begin{abstract}
In this paper, we investigate a geometric property of a class of meromorphic functions. This property implies concavity. A sufficient condition, for a function in this class, is considered utilizing Jack's lemma. We show that, for a meromorphic function $f(z)$, the sufficient condition for concavity is $\mathfrak{R e}\left\{\frac{z f^{\prime \prime \prime}(z)}{f^{\prime \prime}(z)}\right\}<0, z \in U$.
\end{abstract}

\section{Introduction}

A conformal, meromorphic function $f$ on the punctured unit disk $\widehat{U}:=\{z \in \mathbb{C}: 0<|z|<$ $1\}$ is said to be a concave mapping if $f(\widehat{U})$ is the complement of a convex, compact set. Recently, Chuaqui et al. [1] studied the normalized conformal mappings of the disk onto the exterior of a convex polygon via an exemplification formula furnished by the Schwarz lemma. Let $\Sigma$ be the family of functions analytic in the punctured unit disk $\widehat{U}$ of the form

$$
f(z)=\frac{1}{z}+b_{0}+b_{1} z+b_{2} z^{2}+\cdots,
$$

then the necessary and sufficient condition for $f$ to be concave mapping is

$$
1+\mathfrak{R e}\left\{z \frac{f^{\prime \prime}(z)}{f^{\prime}(z)}\right\}<0, \quad z \in \widehat{U}
$$

where

$$
z \frac{f^{\prime \prime}(z)}{f^{\prime}(z)}=-2-2 b_{1} z^{2}-6 b_{2} z^{3}-\left(12 b_{3}+2 b_{1}^{2}\right) z^{4}-\left(20 b_{4}+10 b_{1} b_{2}\right) z^{5}-\cdots .
$$

Furthermore, an analytic function $f \in \widehat{U}$ is called a concave function of order $\alpha \geq 0$ if it satisfies

$$
1+\mathfrak{R e}\left\{z \frac{f^{\prime \prime}(z)}{f^{\prime}(z)}\right\}<-\alpha, \quad z \in \widehat{U} .
$$

Denote this class by $\Sigma_{\alpha}$.

In this work, we investigate a geometric property of a class of meromorphic functions. This property implies concavity. A sufficient condition, for a function in this class, is considered utilizing Jack's lemma. We show that, for a meromorphic function $f(z) \in \Sigma$, a suf-

\section{Springer}

@2014 Ibrahim and Sokół; licensee Springer. This is an Open Access article distributed under the terms of the Creative Commons Attribution License (http://creativecommons.org/licenses/by/2.0), which permits unrestricted use, distribution, and reproduction in any medium, provided the original work is properly cited. 
ficient condition for concavity is

$$
\mathfrak{R e}\left\{\frac{z f^{\prime \prime \prime}(z)}{f^{\prime \prime}(z)}\right\}<0, \quad z \in U
$$

\section{Main result}

We have the following result.

Theorem 2.1 Iff $\in \Sigma$ satisfies the following inequality:

$$
\mathfrak{R e}\left\{\frac{z f^{\prime \prime \prime}(z)}{f^{\prime \prime}(z)}\right\}<0, \quad z \in U
$$

such that

$$
\mathfrak{R e}\left\{\frac{z f^{\prime \prime}(z)}{f^{\prime}(z)}\right\} \neq 0, \quad z \in U,
$$

then $f$ is concave in $\widehat{U}$.

Proof To show that $f$ is concave, we need

$$
\mathfrak{R e}\left\{-1-\frac{z f^{\prime \prime}(z)}{f^{\prime}(z)}\right\}>0, \quad z \in U
$$

Let $\omega(z)$ be a function defined by

$$
-1-\frac{z f^{\prime \prime}(z)}{f^{\prime}(z)}=\frac{1+w(z)}{1-w(z)}
$$

Then $w(z)$ is analytic in $U$ with $w(0)=w^{\prime}(0)=0$ and

$$
\frac{z f^{\prime \prime}(z)}{f^{\prime}(z)}=\frac{-2}{1-w(z)}
$$

Therefore, we need to show that $|w(z)|<1$ in $U$. If not, then there exists a $z_{0} \in U$ such that $\left|w\left(z_{0}\right)\right|=1$. By Jack's lemma $z_{0} w^{\prime}\left(z_{0}\right)=k w\left(z_{0}\right)$, where $k \geq 2$, because $w^{\prime}(0)=0$. By $(2.3)$ we have

$$
-z^{3} f^{\prime \prime}(z)(1-w(z))=2 z^{2} f^{\prime}(z)
$$

Differentiating logarithmically (2.4) with respect to $z$, we conclude

$$
\frac{3 z^{2} f^{\prime \prime}(z)+z^{3} f^{\prime \prime \prime}(z)}{z^{3} f^{\prime \prime}(z)}-\frac{w^{\prime}(z)}{1-w(z)}=\frac{2 z f^{\prime}(z)+z^{2} f^{\prime \prime}(z)}{z^{2} f^{\prime}(z)}
$$

hence

$$
\frac{3 z^{3} f^{\prime \prime}(z)+z^{4} f^{\prime \prime \prime}(z)}{z^{3} f^{\prime \prime}(z)}-\frac{z w^{\prime}(z)}{1-w(z)}=\frac{2 z^{2} f^{\prime}(z)+z^{3} f^{\prime \prime}(z)}{z^{2} f^{\prime}(z)}
$$


and

$$
3+\frac{z^{4} f^{\prime \prime \prime}(z)}{z^{3} f^{\prime \prime}(z)}-\frac{z w^{\prime}(z)}{1-w(z)}=2+\frac{z^{3} f^{\prime \prime}(z)}{z^{2} f^{\prime}(z)} .
$$

It gives for $z=z_{0}$

$$
3+\frac{z_{0} f^{\prime \prime \prime}\left(z_{0}\right)}{f^{\prime \prime}\left(z_{0}\right)}-\frac{z_{0} w^{\prime}\left(z_{0}\right)}{1-w\left(z_{0}\right)}=2+\frac{z_{0} f^{\prime \prime}\left(z_{0}\right)}{f^{\prime}\left(z_{0}\right)} .
$$

By (2.3) and by $z_{0} w^{\prime}\left(z_{0}\right)=k w\left(z_{0}\right)$, where $k \geq 2$, we have

$$
\begin{aligned}
\frac{z_{0} f^{\prime \prime \prime}\left(z_{0}\right)}{f^{\prime \prime}\left(z_{0}\right)} & =\frac{z_{0} w^{\prime}\left(z_{0}\right)}{1-w\left(z_{0}\right)}-1+\frac{z_{0} f^{\prime \prime}\left(z_{0}\right)}{f^{\prime}\left(z_{0}\right)} \\
& =\frac{z_{0} w^{\prime}\left(z_{0}\right)}{1-w\left(z_{0}\right)}-1-\frac{2}{1-w(z)} \\
& =\frac{k w\left(z_{0}\right)}{1-w\left(z_{0}\right)}-1-\frac{2}{1-w(z)} \\
& =\frac{(k+1) w\left(z_{0}\right)-3}{1-w\left(z_{0}\right)} .
\end{aligned}
$$

Because $k+1 \geq 3$, a simple geometric observation yields

$$
\mathfrak{R e}\left\{\frac{(k+1) w\left(z_{0}\right)-3}{1-w\left(z_{0}\right)}\right\} \geq 0
$$

hence

$$
\mathfrak{R e}\left\{\frac{z_{0} f^{\prime \prime \prime}\left(z_{0}\right)}{f^{\prime \prime}\left(z_{0}\right)}\right\} \geq 0 .
$$

This contradicts the assumption (2.1). Therefore, $|w(z)|<1$ in $U$ and (2.2) means that $f$ is concave.

\section{Competing interests}

The authors declare that they have no competing interests.

\section{Authors' contributions}

Both authors jointly worked on deriving the results and approved the final manuscript.

\section{Author details}

${ }^{1}$ Institute of Mathematical Sciences, University Malaya, Kuala Lumpur, 50603, Malaysia. ${ }^{2}$ Department of Mathematics,

Rzeszów University of Technology, Al. Powstańców Warszawy 12, Rzeszów, 35-959, Poland.

\section{Acknowledgements}

This work is supported by University of Malaya High Impact Research Grant no vote UM.C/625/HIR/MOHE/SC/13/2 from Ministry of Higher Education Malaysia. The authors also would like to thank the referees for giving useful suggestions for improving the work.

Received: 22 February 2014 Accepted: 13 March 2014 Published: 26 Mar 2014

\section{References}

1. Chuaqui, M, Duren, P, Osgood, B: Concave conformal mappings and pre-vertices of Schwarz-Christoffel mappings. Proc. Am. Math. Soc. 140, 3495-3505 (2012) 
10.1186/1029-242X-2014-120

Cite this article as: Ibrahim and Sokół: A geometric property for a class of meromorphic analytic functions. Journal of Inequalities and Applications 2014, 2014:120

Submit your manuscript to a SpringerOpen ${ }^{\circ}$ journal and benefit from:

- Convenient online submission

Rigorous peer review

- Immediate publication on acceptance

Open access: articles freely available online

- High visibility within the field

- Retaining the copyright to your article

Submit your next manuscript at $\boldsymbol{s p r i n g e r o p e n . c o m ~}$ 